Check for updates

Cite this: RSC Adv., 2021, 11, 17108

Received 6th March 2021

Accepted 3rd April 2021

DOI: $10.1039 / \mathrm{d} 1 \mathrm{ra01790j}$

rsc.li/rsc-advances

\section{Design, synthesis, and catalytic performance of modified graphene oxide based on a cobalt complex as a heterogenous catalyst for the preparation of aminonaphthoquinone derivatives $\uparrow$}

\begin{abstract}
Mahnaz Mirheidari (D) and Javad Safaei-Ghomi (D) *
We are reporting a functionalized graphene oxide catalyst developed by modifying graphene oxide surface using the covalent attachment of an amino-functionalized $\mathrm{SiO}_{2}$ sphere/cobalt complex. Silica network has special characteristics including mechanical strength, high thermal and chemical stability with good dispersion in solvents. The silica/graphene oxide mixture provides improved properties and extends the scope of application. Graphene oxide was functionalized by spherical silica with the help of hybrid silane-containing nitrogen to coordinate with Co(॥) for increasing the catalytic activity. The catalyst was characterized by Fourier Transform Infrared (FT-IR) spectroscopy, powder X-ray diffraction (XRD), Energy Dispersive X-ray (EDX), Scanning Electron Microscopy (SEM), Raman spectroscopy, and Thermal Gravimetric (TGA) analyses. The catalyst showed high catalytic activity for multi-component reactions in the synthesis of aminonaphthoquinones in ethanol solvent. The catalyst's ability to improve the yield (96-98\%), reduce the reaction time (5-8 $\mathrm{min})$, and recycling ability are important benefits for the catalyst.
\end{abstract}

\section{Introduction}

Graphene is one form of carbon material with 2D layered structure that is considered as an excellent catalyst support in recent decades. Geim and Novoselov explored a single layer of graphene through crystal graphite in 2004 for the first time. ${ }^{1}$ Graphene has different applications in various fields including solar cells, ${ }^{2}$ polymer nanocomposites, ${ }^{3}$ and biological nanocomposites $^{4}$ due to its elasticity, chemical stability, and high specific surface area as well as electrical and heat conductivity. ${ }^{5-7}$

Graphene oxide (GO) is the oxidised form of graphene, which has a two-dimensional monolayer honeycomb structure. It is a good precursor material for fabrication in large quantities due to its low-cost and easily scalable synthesis process. In addition, modification of graphene oxide is simple due to chemical interaction between oxygen functional groups on the surface, making it a desirable support in chemical reactions. ${ }^{8-10}$ Several methods have been developed for GO synthesis, however, Hummers' method is the most well-known approach. ${ }^{11}$

The oxygen-containing functional groups that are distributed over the GO surface can act as an active site, and can be attacked by nucleophiles to change the surface of graphene

Department of Organic Chemistry, Faculty of Chemistry, University of Kashan, P.O. Box 87317-51167, Kashan, I. R. Iran. E-mail: safaei@kashanu.ac.ir

$\dagger$ Electronic supplementary information (ESI) available. See DOI: 10.1039/d1ra01790j sheets. Therefore, graphene oxide is widely used as a catalyst support. ${ }^{12,13}$ Functionalized graphene oxide has several applications in biomedical, electrochemical, and chemical fields. ${ }^{14}$ In addition, functionalized GO with various metals has been extensively used for organic transformations. ${ }^{15,16}$

As far as we know, among different surface modifying agents, polysiloxane-like silane coupling agents are often applied to obtain modified graphene sheets. ${ }^{17,18}$ During the coupling procedure, the covalent bonds between the functional groups of silane with graphene oxide lead to increased graphene oxide performance in the catalytic field and deliver multifunctional characteristics. ${ }^{19-21}$ Silica $\left(\mathrm{SiO}_{2}\right)$ increases the corrosion resistance and thermal resistance of graphene oxide, which may improve the loading of catalytically active sites, having significant application potential in different fields. ${ }^{22-27}$ In addition, cobalt has obtained more attention because of being an earth-abundant metal, catalytic activities, ${ }^{28,29}$ and photocatalytic $\mathrm{H}_{2}$ production. ${ }^{30}$

2-Hydroxy-1,4-napthoquinone (lawsone) has been known for almost 4000 years, which is present in the leaves of the henna plant, and it is a significant source of natural dyes. ${ }^{31}$ The compounds containing the naphthoquinone structure received a great deal of attention because of various biological features such as molluscicidal, ${ }^{32}$ antitumor, ${ }^{33}$ antifungal, and antibacterial ${ }^{34}$ activities as well as fluorescence behavior. ${ }^{35}$

Research shows that the incorporation of nitrogen atom containing functional groups such as amino group or nitrogen 

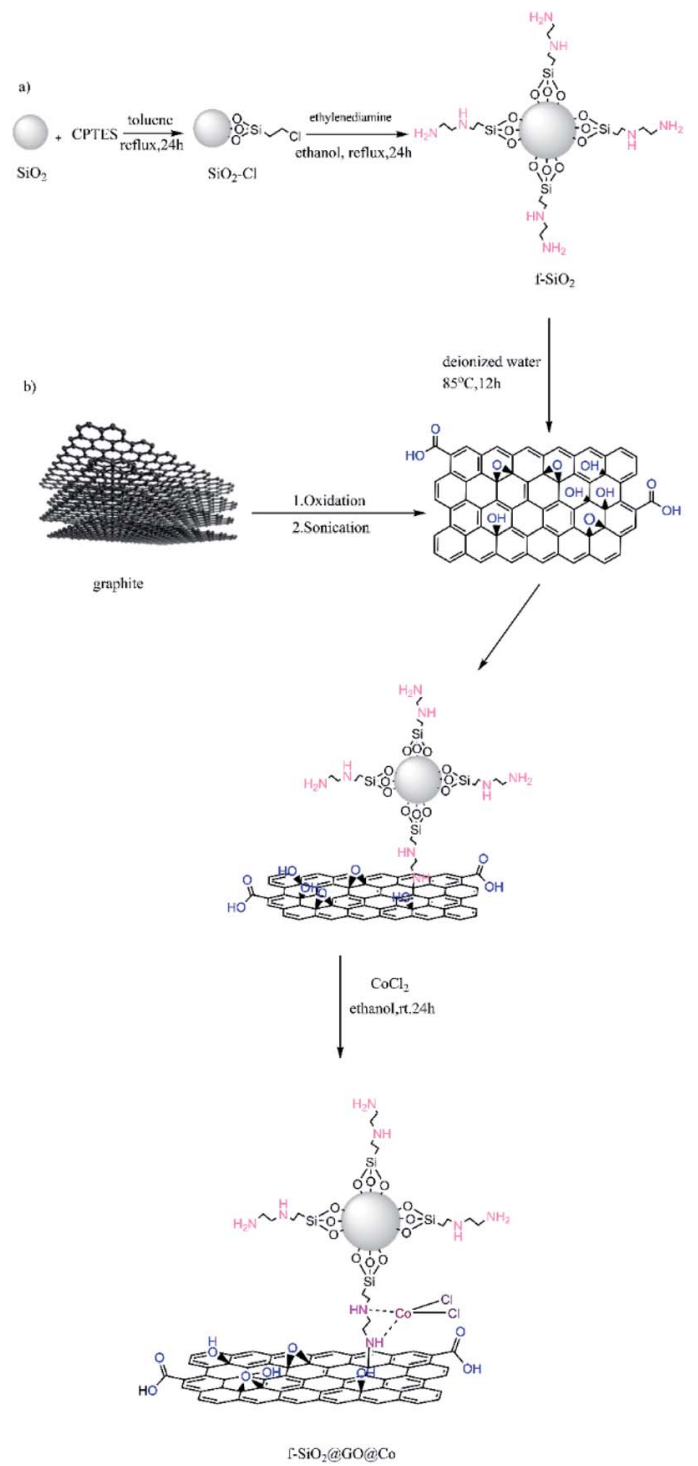

Scheme 1 Different steps of synthesis of $\mathrm{f}-\mathrm{SiO}_{2} @ \mathrm{aGO} @ \mathrm{Co}$

atom into the naphthoquinone framework often improves anticancer, ${ }^{36}$ molluscicidal, ${ }^{37}$ and antibacterial activities. ${ }^{38}$

Considering the above-mentioned properties of graphene oxide, in the current study, the GO surface was activated with amino-functionalized $\mathrm{SiO}_{2}$ containing binding sites for coordination to $\mathrm{Co}$ (II) for increasing the catalytic activity. The produced catalyst as the highly efficient heterogeneous catalyst was used for the synthesis of aminonaphthoquinone derivatives through a three-component condensation reaction of lawsone, aromatic aldehydes, and aromatic amines in the presence of ethanol at room temperature (Scheme 1).

\section{Experimental}

\subsection{General}

All materials were commercially purchased from Merck and Sigma-Aldrich. Melting points of the products were recorded by an Electrothermal 9200 system. Fourier transform infrared measurements were carried out on a Magna 550 instrument by using potassium bromide ( $\mathrm{KBr})$ plates. The ${ }^{1} \mathrm{H}$ NMR and ${ }^{13} \mathrm{C}$ NMR spectra were determined on a Bruker Avance-400 spectrometer with DMSO- $\mathrm{d}_{6}$. The X-ray diffraction patterns were collected on an X-ray diffractometer (PHILIPS, PW 1510, Netherland). Scanning Electron Microscopy and Energy Dispersive Xray analysis (MIRA3-TESCAN FESEM) was used to provide information about morphology and elemental composition. Raman spectra were recorded using a Takram N1-541 Raman spectrometer (Teksan, Tehran, Iran). Thermal analysis was carried out on a STA 503 (Bahr) instrument.

\subsection{Synthesis of graphene oxide}

Graphite powder $(1 \mathrm{~g})$ along with $0.5 \mathrm{~g}$ sodium nitrate were dissolved in $25 \mathrm{ml}$ of sulphuric acid (98\%) for 10 minutes and then $3 \mathrm{~g}$ potassium carbonate was added to the mixture while the temperature increased to $35{ }^{\circ} \mathrm{C}$ with further stirring for $30 \mathrm{~min}$. Afterward, the solution was added to DI water $(100 \mathrm{ml})$ and stirred for 15 minutes at $95^{\circ} \mathrm{C}$. Then, $10 \mathrm{ml}(30 \% \mathrm{w} / \mathrm{w}) \mathrm{H}_{2} \mathrm{O}_{2}$ was added to the solution. The obtained brown solution was centrifuged, washed thoroughly with $\mathrm{HCl}$ and DI water, and dried at $60^{\circ} \mathrm{C}$ for $12 \mathrm{~h}$. Finally, the dried solid was dispersed in distilled $\mathrm{H}_{2} \mathrm{O}$ by sonication, then centrifuged and dried again at $60{ }^{\circ} \mathrm{C}$ for $24 \mathrm{~h}$.

\subsection{Synthesis of spherical silicon dioxide nanoparticles}

The mixture of EtOH $(50 \mathrm{ml})$ and DI water $(20 \mathrm{ml})$ was ultrasonicated for 30 minutes. Then, the solution of tetraethyl orthosilicate $(3 \mathrm{ml})$ and PVP $(0.1 \mathrm{mmol})$ in $5 \mathrm{ml}$ ethanol was added dropwise to a mixture by vigorous stirring. Ethylenediamine $(0.1 \mathrm{ml})$ as a precipitating agent was slowly added to the solution under sonication. After 30 minutes, the obtained silicon dioxide $\left(\mathrm{SiO}_{2}\right)$ was collected and washed thoroughly with EtOH and $\mathrm{H}_{2} \mathrm{O}$ and then was dried at $80{ }^{\circ} \mathrm{C}$.

\subsection{Synthesis of ethylenediamine group@silicon dioxide}

At first, refluxing silicon dioxide $(1 \mathrm{~g})$ with $0.5 \mathrm{ml}$ 3-chloropropyl triethoxysilane (CPTES) was done in $30 \mathrm{ml}$ dry toluene for $24 \mathrm{~h}$. The obtained product was centrifuged and washed with toluene several times and then dried for $8 \mathrm{~h}$ at $120{ }^{\circ} \mathrm{C}$. Then, $0.3 \mathrm{~g}$ ethylenediamine was added to a solution containing $1 \mathrm{~g}$ of $\mathrm{SiO}_{2} @$ @CPTES in $30 \mathrm{ml} \mathrm{EtOH}$ and refluxed for $24 \mathrm{~h}$. The obtained solid was filtered and washed with water and EtOH and finally dried for $10 \mathrm{~h}$ under $90{ }^{\circ} \mathrm{C}$.

\subsection{Synthesis of ethylenediamine-functionalized $\mathrm{SiO}_{2} @$ graphene oxide}

$0.04 \mathrm{~g}$ GO, $20 \mathrm{ml}$ DI water, and $0.16 \mathrm{~g} \mathrm{SiO}_{2} @$ @ethylenediamine were added to a round-bottom flask and dispersed under ultrasonic irradiation for 20 minutes. Then, the sonicated solution was stirred for $12 \mathrm{~h}$ at $85^{\circ} \mathrm{C}$ and the solid material was centrifuged, washed with EtOH and DI water to remove impurities, and dried overnight at $60{ }^{\circ} \mathrm{C}$. 


\subsection{Synthesis of ethylenediamine-functionalized} $\mathrm{SiO}_{2} @ g r a p h e n e$ oxide@cobalt

$1 \mathrm{~g}$ ethylenediamine-functionalized $\mathrm{SiO}_{2} @$ graphene oxide, $0.01 \mathrm{wt} \%$ cobalt(II) chloride and $5 \mathrm{ml}$ absolute $\mathrm{EtOH}$ were added to a flask and dispersed under ultrasound for 5 minutes to obtain a uniform dispersion after mixing. The uniform mixture was stirred at RT for $24 \mathrm{~h}$. The final product was then separated and washed with EtOH and DI water and dried at RT.

\subsection{General procedure for the synthesis of aminonaphthoquinone derivatives}

To a mixture of lawsone $(1 \mathrm{mmol})$ and the respective amine (1 $\mathrm{mmol})$ in ethanol $(5 \mathrm{ml}), 20 \mathrm{wt} \%$ catalyst was added. After stirring for 10 minutes at room temperature (RT), the corresponding benzaldehyde $(1 \mathrm{mmol})$ was added and stirred until the reaction was completed (monitored by TLC). The produced solid was purified by cold ethanol and water to afford the pure product.

\section{Results and discussion}

\subsection{Characterization of catalyst}

The synthesized catalyst (f-SiO $\mathrm{S}_{2} @ G O @ \mathrm{Co}$ ) includes the properties of functionalized $\mathrm{SiO}_{2}$ and GO. The FT-IR spectrum of distinct steps for the catalyst is presented in Fig. 1. Graphene oxide showed peaks at $3398 \mathrm{~cm}^{-1}, 1721 \mathrm{~cm}^{-1}, 1383$, and $1060 \mathrm{~cm}^{-1}$, which were attributed to the O-H group stretching

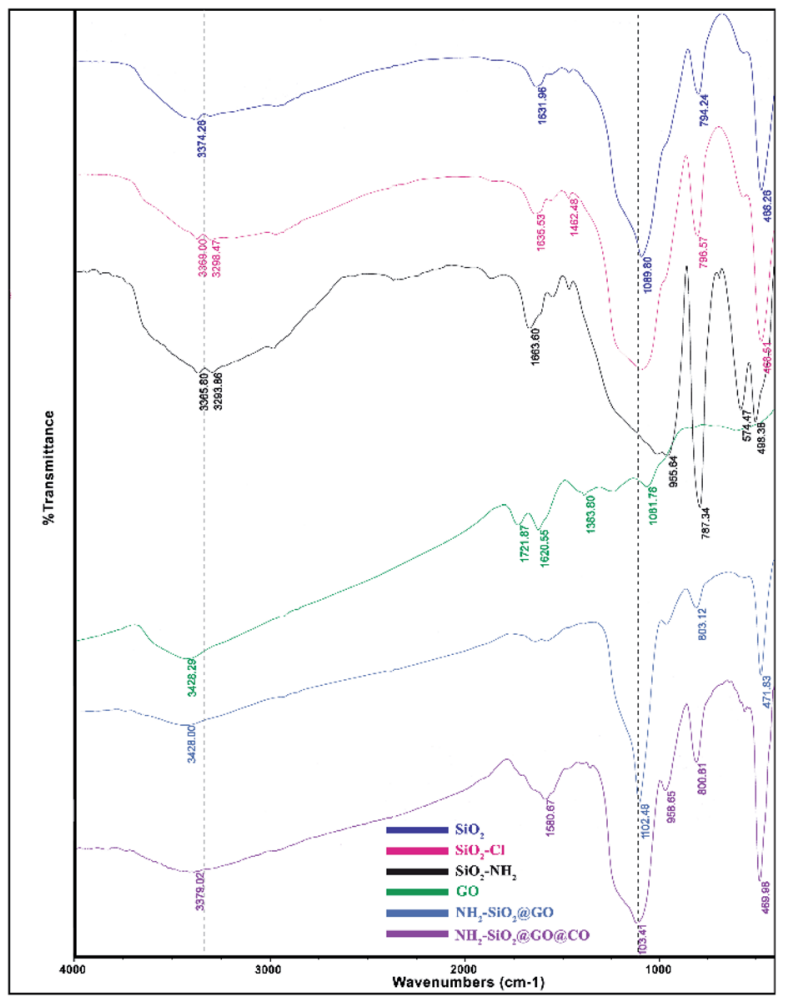

Fig. 1 FT-IR spectra of $\mathrm{SiO}_{2}, \mathrm{SiO}_{2} @ \mathrm{aCl} \mathrm{SiO}_{2} \mathrm{aNH}_{2}, \mathrm{GO}, \mathrm{f}-\mathrm{SiO}_{2} \mathrm{aGO}$, and $\mathrm{f}-\mathrm{SiO}_{2} \mathrm{aGO}$ aCo.

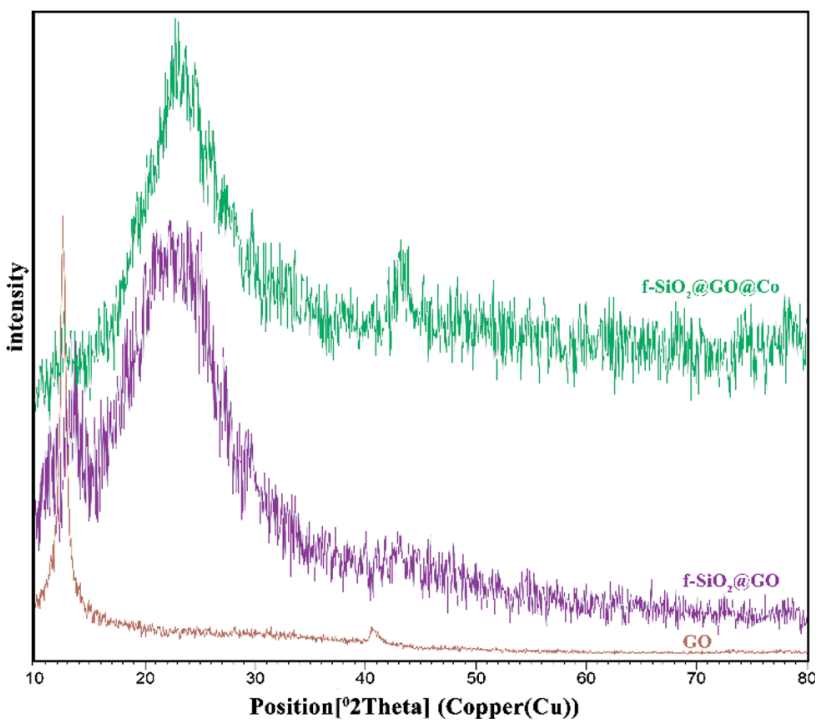

Fig. 2 XRD patterns of $\mathrm{GO}, \mathrm{f}-\mathrm{SiO}_{2} \mathrm{aGO}$, and $\mathrm{f}-\mathrm{SiO}_{2} \mathrm{aGO} \mathrm{aCo}$.

vibrations, carbonyl stretch for carboxylic acid, C-O stretching, and epoxy group vibrations, respectively. For $\mathrm{SiO}_{2}$, the absorption peaks at $798,1089 \mathrm{~cm}^{-1}$, and $3370 \mathrm{~cm}^{-1}$ were attributed to asymmetric vibrations of the $\mathrm{Si}-\mathrm{O}-\mathrm{Si}$ bonds and $\mathrm{O}-\mathrm{H}$ groups. In $\mathrm{SiO}_{2} @ \mathrm{Cl}$ and $\mathrm{SiO}_{2}$ @ethylenediamine spectra, the bands at around $950 \mathrm{~cm}^{-1}$ were related to ethoxy stretching vibrations. After grafting functionalized $\mathrm{SiO}_{2}$ onto graphene oxide, the band at $1102 \mathrm{~cm}^{-1}$ confirmed the successful formation of $\mathrm{f}$ $\mathrm{SiO}_{2} @ G O @ \mathrm{Co}$.

The XRD pattern for graphene oxide sheets showed a strong peak at about $2 \theta=12^{\circ}$, which revealed the exfoliation of GO and intercalation of water molecules in the graphite structure such that oxygen functional groups result between graphite layers. ${ }^{39}$ After the functionalization of graphene oxide, the removal of many oxygen-containing functional groups on the surface of graphene oxide cause the intensity of the peak at $2 \theta=12^{\circ}$ to decrease. Also, the broad peak at $2 \theta=25^{\circ}$ and $2 \theta=44^{\circ}$ corresponded to the amorphous silica and Co, which suggests the successful synthesis of the desired catalyst (Fig. 2).

The SEM analysis for graphene oxide (Fig. 3a) shows the layered structure with crumpled morphology at the sheet edges.

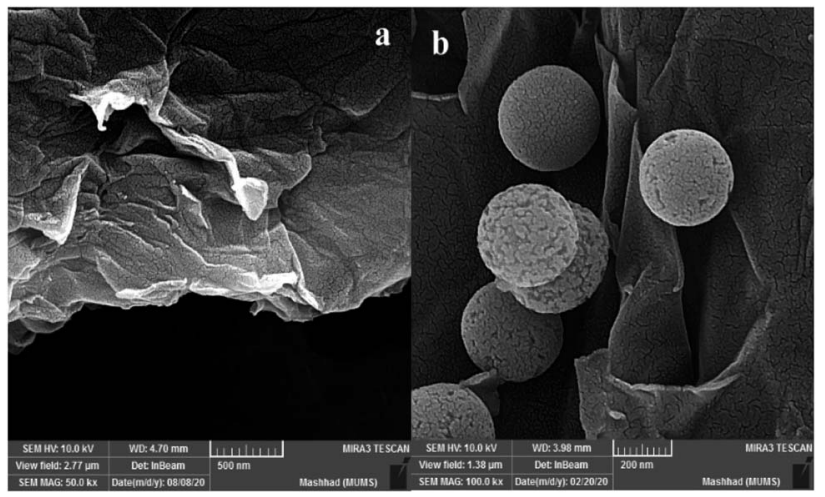

Fig. 3 FE-SEM images of $\mathrm{GO}$ (a) $\mathrm{f}-\mathrm{SiO}_{2} \mathrm{aGO}(\mathrm{Co}$ (b). 

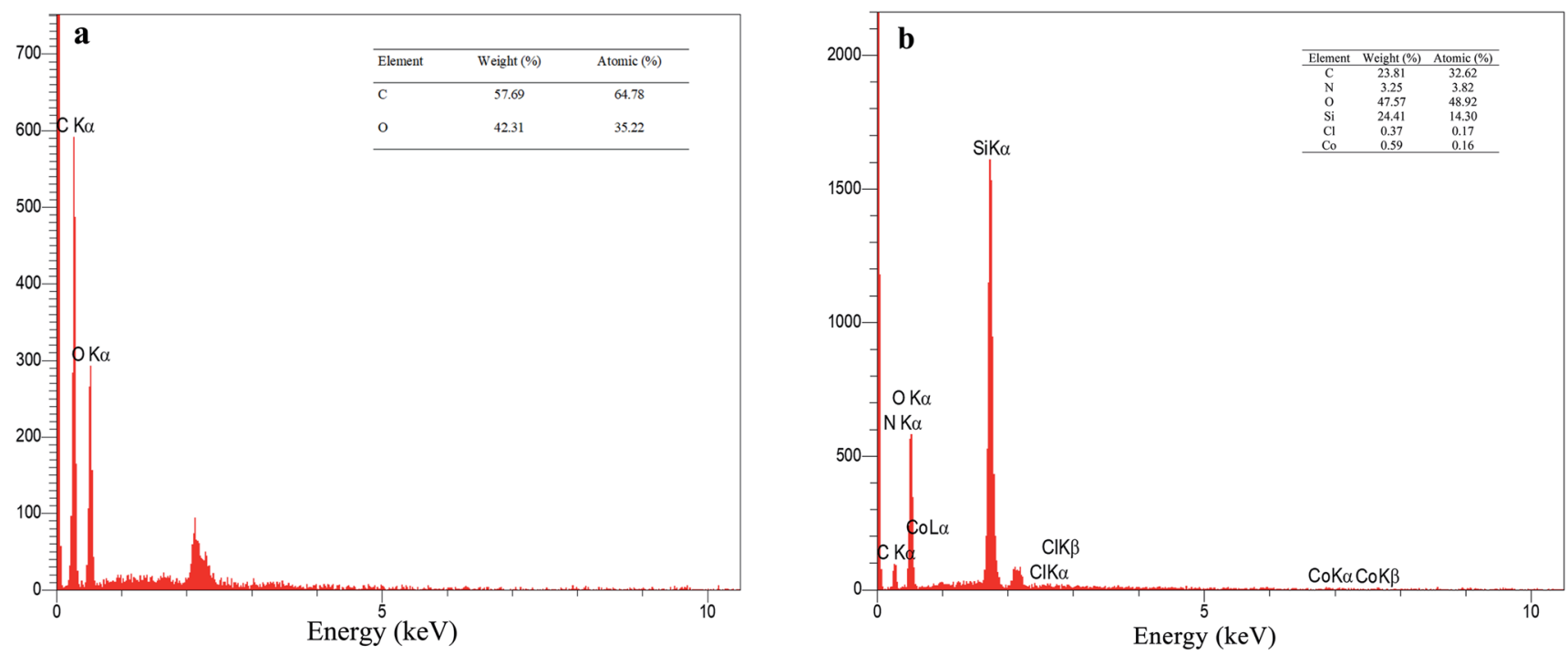

Fig. 4 EDS spectra of $\mathrm{GO}(\mathrm{a})$ and $\mathrm{f}-\mathrm{SiO}_{2} \mathrm{aGO}(\mathrm{CCo}(\mathrm{b})$.

Functionalized graphene oxide (Fig. $3 \mathrm{~b}$ ) exhibits the distribution of functionalized spherical silica nanoparticles on the surface of graphene oxide sheets.

The EDX analysis for graphene oxide and f-SiO $\mathrm{S}_{2} @ G \mathrm{GOC}$ catalyst are presented in Fig. 4. According to the data for graphene oxide EDX (Fig. 4a), the carbon and oxygen contents for graphene oxide (atomic percentage) were $64.78 \%$ and $35.22 \%$, respectively, and the ratio of carbon to oxygen was $\mathrm{C} / \mathrm{O}=1.83$. The atomic percentage of $\mathrm{C}, \mathrm{N}, \mathrm{O}, \mathrm{Si}, \mathrm{Cl}$, Co was $32.62 \%, 3.82 \%, 48.92 \%$, $14.30 \%, 0.17 \%, 0.16 \%$, respectively. In the elemental analysis of $\mathrm{f}-$ $\mathrm{SiO}_{2} @ G O @ \mathrm{GO}, \mathrm{SiO}_{2}$ moiety in the catalyst structure reduced the carbon amount (32.62\%) and increased the oxygen amount $(48.92 \%)$, which resulted in a carbon to oxygen ratio of $\mathrm{C} / \mathrm{O}=0.66 .^{40}$

The Raman spectra were used for the identification of structural properties of GO and GO@f-SiO ${ }_{2} @ \mathrm{Co}$ (Fig. 5). Two characteristic peaks for graphene oxide at $1595 \mathrm{~cm}^{-1}$ (in-plane vibrations of $\mathrm{sp}^{2}$ bonded carbon) and $1338 \mathrm{~cm}^{-1}$ (out of plane vibrations) were related to $\mathrm{G}$ and $\mathrm{D}$ bands, respectively. The Raman spectrum

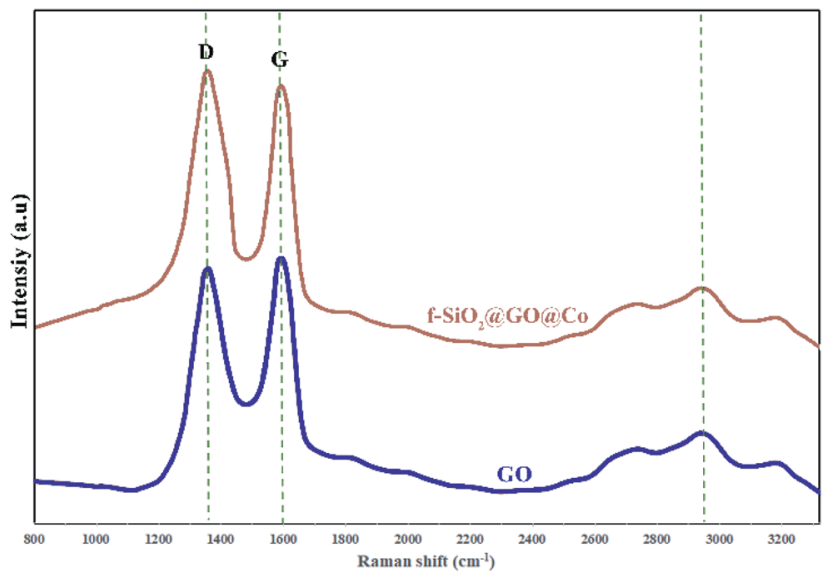

Fig. 5 The Raman spectra for $\mathrm{GO}$ and $\mathrm{f}-\mathrm{SiO}_{2} \mathrm{aGO} @ \mathrm{Co}$. for functionalized graphene oxide showed similar peaks, while $I_{\mathrm{D}} /$ $I_{\mathrm{G}}$ ratio increased compared to $I_{\mathrm{D}} / I_{\mathrm{G}}$ of graphene oxide, indicating the formation of more $\mathrm{sp}^{3}$ carbon in $\mathrm{f}-\mathrm{SiO}_{2} @ \mathrm{GO} @ \mathrm{Co}$ from the grafting of $\mathrm{f}-\mathrm{SiO}_{2}$ on graphene oxide. ${ }^{41,42}$

Thermogravimetric analysis (TGA) of the catalyst was carried out and the result is shown in Fig. 6. The TGA spectrum of graphene oxide shows that it is unstable, with weight loss even below $100^{\circ} \mathrm{C}$ corresponding to the removal of absorbed water. ${ }^{43}$ In TGA of the catalyst, the primary loss occurred at around $200{ }^{\circ} \mathrm{C}$, which was attributed to the pyrolysis of the functional groups containing oxygen. ${ }^{44}$ Decomposition of the catalyst after $230{ }^{\circ} \mathrm{C}$, that continues to $800{ }^{\circ} \mathrm{C}$ indicated the thermal stability of the catalyst and related to the decomposition of functional groups in $\mathrm{GO}^{45}$

To show the efficiency of the catalyst, we tested its potential in the model reaction. For this purpose, different parameters such as solvents, variety of catalysts, time, and the amount of the desired catalyst were evaluated on the model reaction.

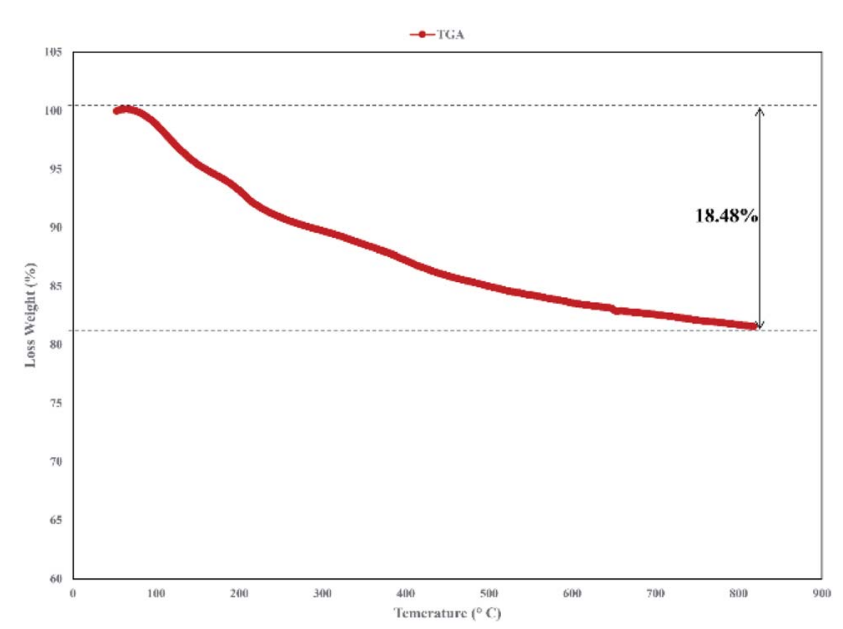

Fig. 6 The TGA analysis for $\mathrm{f}-\mathrm{SiO}_{2} \mathrm{aGO}$ aCo. 
Table 1 The results of different catalysts on the model reaction ${ }^{a}$

\begin{tabular}{|c|c|c|c|}
\hline Entry & Catalyst & Time $^{b}$ & Yield $^{c}(\%)$ \\
\hline 1 & - & $20 \mathrm{~h}$ & - \\
\hline 2 & NiO NPs & $7 \mathrm{~h}$ & $40 \%$ \\
\hline 3 & $\mathrm{SiO}_{2} \mathrm{NPs}$ & $3 \mathrm{~h}$ & $60 \%$ \\
\hline 4 & $\mathrm{NiO} @ \mathrm{SiO}_{2} \mathrm{NPs}$ & $3 \mathrm{~h}$ & $52 \%$ \\
\hline 5 & $\mathrm{f}-\mathrm{SiO}_{2} @ \mathrm{Fe}_{3} \mathrm{O}_{4}$ & $1 \mathrm{~h}$ & $70 \%$ \\
\hline 6 & f-SiO ${ }_{2} @ G O$ & $30 \mathrm{~min}$ & $85 \%$ \\
\hline 7 & f-SiO ${ }_{2} @ G O @ C o$ & $5 \mathrm{~min}$ & $98 \%$ \\
\hline
\end{tabular}

${ }^{a}$ Reaction conditions: 2-hydroxynaphthoquinone (1 mmol), 4nitrobenzaldehyde $(1 \mathrm{mmol}), 3$-nitro aniline $(1 \mathrm{mmol})$, different catalysts $(20 \mathrm{mg})$, RT. stirring. ${ }^{b}$ Reaction progress monitored by TLC. ${ }^{c}$ Isolated yield.

In order to display the superiority of the catalyst, different catalysts were compared to a model reaction (4b). First, the reaction was performed without the catalyst and no product was formed after $20 \mathrm{~h}$ (Table 1, entry 1). Then, different nanoparticles were used and the obtained yield was checked. The nanoparticles resulted in low yield. Functionalized $\mathrm{SiO}_{2}$ was then used on $\mathrm{Fe}_{3} \mathrm{O}_{4}$ and graphene oxide support. The obtained result showed that graphene oxide was a better support with more activity. Finally, f-SiO $\mathrm{S}_{2} @ \mathrm{GO}$ and $\mathrm{f}-\mathrm{SiO}_{2} @ \mathrm{GO} @ \mathrm{Co}$ were compared. f-SiO $\mathrm{S}_{2} @ \mathrm{GO} @ \mathrm{Co}$ resulted to have more acidic sites and better catalytic efficiency with the maximum yield (98\%) in a minimum time (Table 1 , entry 7 ).

In continuation, different protic (ethanol, water, and ethanol/ water) and aprotic (acetonitrile, THF, and toluene) solvents were tested in the presence of $\mathrm{f}-\mathrm{SiO}_{2} @ \mathrm{GO} @ \mathrm{Co}(20 \%)$ as a catalyst. The results indicated that the reaction in the presence of protic solvents was faster than that in the presence of aprotic solvents and the final yields ranged between $87 \%$ and $98 \%$. The best protic solvent was ethanol, which resulted in $98 \%$ yield of appropriate product in minimum reaction time (Table 2, entry 2).

Then, the effect of 10 and $20 \%(\mathrm{w} / \mathrm{w}) \mathrm{f}_{-}-\mathrm{SiO}_{2}$ loading on the GO surface was evaluated. The result indicated that $20 \%(\mathrm{w} / \mathrm{w}) \mathrm{f}-$ $\mathrm{SiO}_{2}$ on the surface of GO increases the catalyst's efficiency. Then, the impact of $\mathrm{f}_{-} \mathrm{SiO}_{2} @ \mathrm{GO} @ \mathrm{Co}$ amount in the reaction was evaluated (Table 3, entries 1-5). The obtained result exhibited that the catalyst loading of $20 \mathrm{wt} \%$ increased the yield up to $98 \%$ (Table 3, entry 4) while loading higher than $20 \mathrm{wt} \%$ did not have any impact on improving the yield. After finding the best

Table 2 Evaluation of different solvents on the model reaction ${ }^{a}$

\begin{tabular}{|c|c|c|c|}
\hline Entry & Solvent & Time $^{b}$ & Yield $^{c}(\%)$ \\
\hline 1 & THF & $150 \mathrm{~min}$ & $42 \%$ \\
\hline 2 & Ethanol & $5 \mathrm{~min}$ & $98 \%$ \\
\hline 3 & Water & $50 \mathrm{~min}$ & $87 \%$ \\
\hline 4 & Ethanol/water & $50 \mathrm{~min}$ & $92 \%$ \\
\hline 5 & Toluene & $200 \mathrm{~min}$ & $30 \%$ \\
\hline 6 & Acetonitrile & $90 \mathrm{~min}$ & $42 \%$ \\
\hline
\end{tabular}

${ }^{a}$ Reaction conditions: 2-hydroxynaphthoquinone (1 mmol), 4nitrobenzaldehyde $(1 \mathrm{mmol})$, 3-nitroaniline $(1 \mathrm{mmol}), \mathrm{f}-\mathrm{SiO}_{2} @ \mathrm{GO} @ \mathrm{Co}$ $(20 \%)$, different solvents, RT. stirring. ${ }^{b}$ Reaction progress monitored by TLC. ${ }^{c}$ Isolated yield.
Table 3 Evaluation of catalyst loading for upgrading the yield of the reaction $^{a}$

\begin{tabular}{llll}
\hline Entry & Catalyst loading & Time $^{b}$ & Yield $^{c}(\%)$ \\
\hline 1 & 5 & $2 \mathrm{~h}$ & $62 \%$ \\
2 & 10 & $90 \mathrm{~min}$ & $74 \%$ \\
3 & 15 & $45 \mathrm{~min}$ & $85 \%$ \\
4 & 20 & $\mathbf{5}$ min & $\mathbf{9 8 \%}$ \\
5 & 30 & $5 \mathrm{~min}$ & $98 \%$
\end{tabular}

${ }^{a}$ Reaction conditions: 2-hydroxynaphthoquinone (1 mmol), 4nitrobenzaldehyde (1 mmol), 3-nitro aniline (1 mmol), f$\mathrm{SiO}_{2} @ G O @ \mathrm{Co}$ different amounts, RT. stirring. ${ }^{b}$ Reaction progress monitored by TLC. ${ }^{c}$ Isolated yield.

Table 4 Synthesis of aminonaphthoquinone derivatives by $\mathrm{f}-\mathrm{SiO}_{2} \mathrm{a}$ GO@Co as a catalyst

\begin{tabular}{llllll}
\hline Entry & Aldehyde & Amine & Product & Time (min) & Yield (\%) \\
\hline 1 & $4-\mathrm{Cl}$ & $4-\mathrm{NO}_{2}$ & $\mathbf{4 a}$ & 5 & $98 \%$ \\
2 & $4-\mathrm{NO}_{2}$ & $3-\mathrm{NO}_{2}$ & $\mathbf{4 b}$ & 5 & $98 \%$ \\
3 & $3-\mathrm{OH}$ & $4-\mathrm{NO}_{2}$ & $\mathbf{4 c}$ & 7 & $96 \%$ \\
4 & $3-\mathrm{NO}_{2}$ & $3-\mathrm{NO}_{2}$ & $\mathbf{4 d}$ & 7 & $97 \%$ \\
5 & $2-\mathrm{OH}$ & $4-\mathrm{NO}_{2}$ & $\mathbf{4 e}$ & 8 & $96 \%$ \\
6 & $4-\mathrm{CH}_{3}$ & $4-\mathrm{NO}_{2}$ & $\mathbf{4 f}$ & 7 & $96 \%$ \\
7 & $\mathrm{Ph}$ & $4-\mathrm{NO}_{2}$ & $\mathbf{4 g}$ & 6 & $96 \%$ \\
8 & $2-\mathrm{OH}-5-\mathrm{Br}$ & $4-\mathrm{NO}_{2}$ & $\mathbf{4 h}$ & 6 & $96 \%$ \\
9 & $4-\mathrm{OCH}_{3}$ & $4-\mathrm{NO}_{2}$ & $\mathbf{4 i}$ & 7 & $96 \%$ \\
10 & $\left.4-\mathrm{N}_{2} \mathrm{CH}_{3}\right)_{2}$ & $4-\mathrm{NO}_{2}$ & $\mathbf{4 j}$ & 7 & $96 \%$ \\
11 & $3,4-\mathrm{Dimethoxy}$ & $4-\mathrm{NO}_{2}$ & $\mathbf{4 k}$ & 7 & $95 \%$ \\
12 & $2-\mathrm{NO}_{2}$ & $4-\mathrm{NO}_{2}$ & $\mathbf{4 1}$ & 5 & $96 \%$
\end{tabular}

conditions for the reaction, aminonaphthoquinone derivatives in the presence of the catalyst $(20 \%)$ at room temperature in ethanol were synthesized (Table 4).

\subsection{Reusability of the catalyst}

The reusability of the catalyst was examined by conducting the recyclability test in the model reaction $(\mathbf{4 b})$. The catalyst was separated at the end of the reaction by centrifugation and

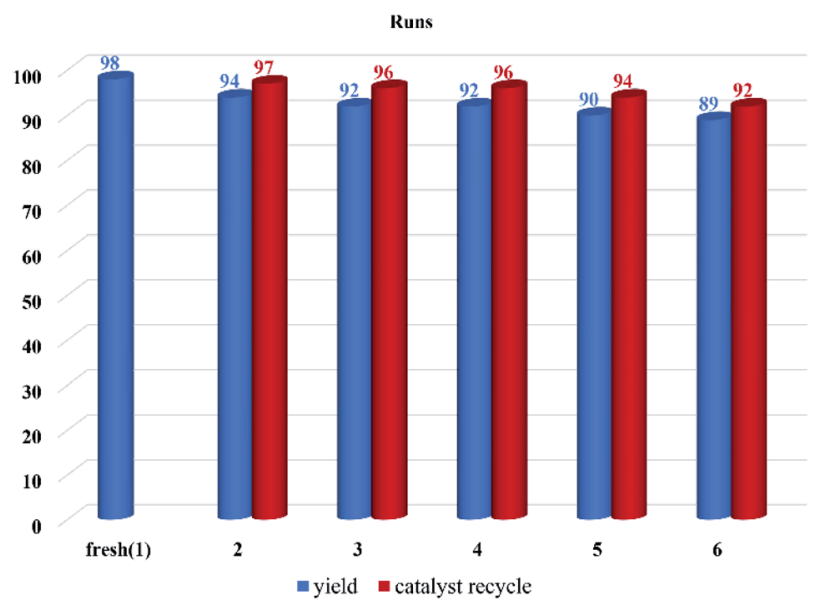

Fig. 7 Recycling results of $\mathrm{f}-\mathrm{SiO}_{2} \mathrm{aGO} a \mathrm{Co}$ on the model reaction. 

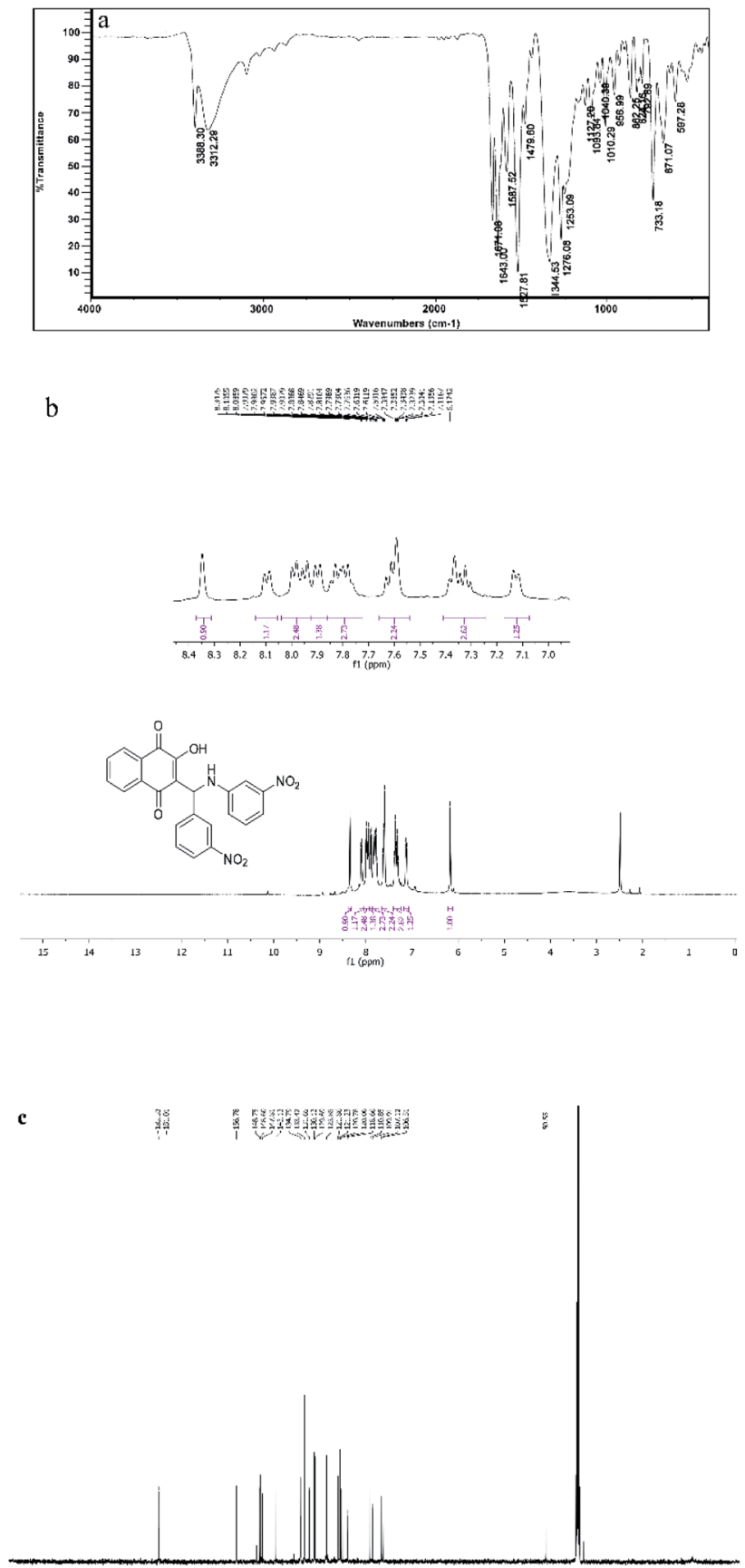

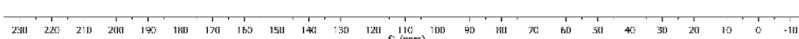

Fig. 8 FT-IR, ${ }^{1}$ HNMR, ${ }^{13}$ CNMR spectra of compound $4 \mathrm{~d}$. washed with ethyl acetate to remove impurities. The catalyst was used six times with a great average recycling value (95\%). The results showed that the catalytic activity decreased from $98 \%$ in the first run (fresh) to $89 \%$ after the completion of the sixth run (Fig. 7).

\subsection{Analysis and characterization of the synthesized compound}

All the synthesized compounds (4a-1) were characterized with different methods such as FT-IR and ${ }^{1} \mathrm{H}$ NMR and ${ }^{13} \mathrm{C}$ NMR spectroscopy. The IR spectrum of the selected compound (4d) shows peaks at 3388 and $3312 \mathrm{~cm}^{-1}$, which were related to $\mathrm{OH}$ and $\mathrm{NH}$ symmetric stretching vibrations. The band at

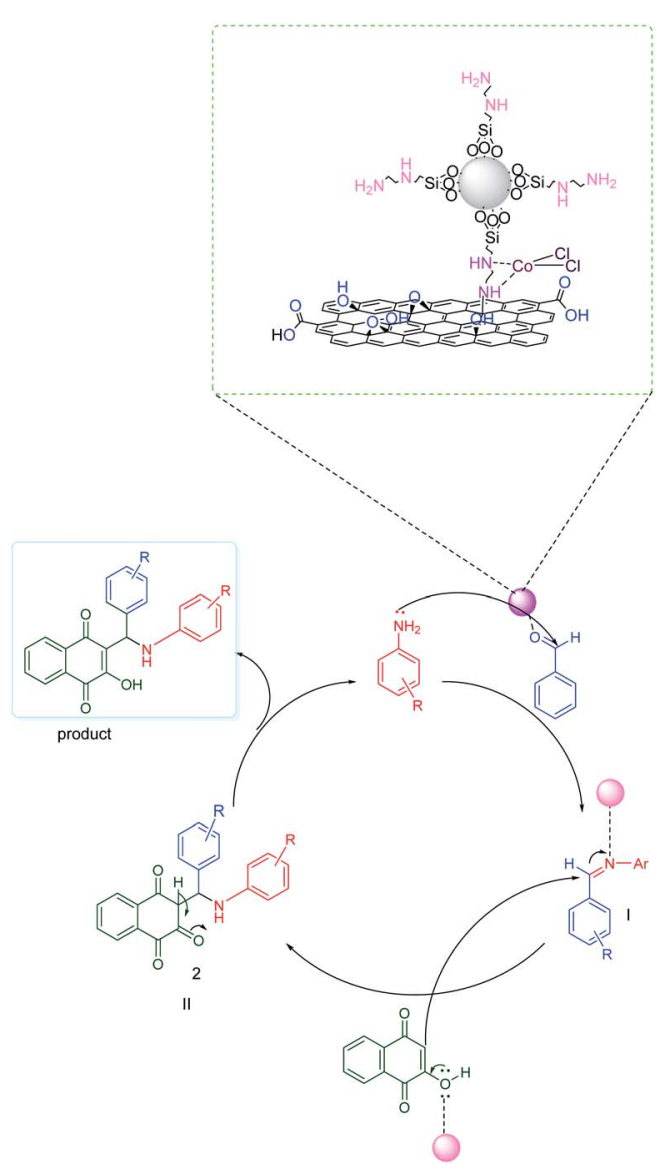

Scheme 2 A proposed mechanism for the synthesis of aminonaphthoquinone derivatives.

Table 5 Comparison of the catalytic potential of $\mathrm{f}-\mathrm{SiO}_{2} \mathrm{aGO}$ aCo with previously reported catalysts for the synthesis of aminonaphthoquinone

\begin{tabular}{|c|c|c|c|c|c|c|}
\hline 1 & Montmorillonite-k10 & Ethanol & r.t. & $8 \mathrm{~h}$ & 93 & 46 \\
\hline 2 & PPA & $\mathrm{H}_{2} \mathrm{O}$ & Ambient & $6 \mathrm{~h}$ & 87.9 & 47 \\
\hline 4 & $\gamma-\mathrm{Fe}_{2} \mathrm{O}_{3} / \mathrm{SiO}_{2}$-propyl-NH-AMAM-SO ${ }_{3} \mathrm{H}$ & Solvent-free & Ambient condition & $3 \mathrm{~h}$ & 93 & 49 \\
\hline 5 & f-SiO2@GO@Co & Ethanol & r.t. & $5 \mathrm{~min}$ & $98 \%$ & This work \\
\hline
\end{tabular}


$1642 \mathrm{~cm}^{-1}$ was for $\mathrm{C}=\mathrm{O}$ stretching vibration (Fig. 8a). The ${ }^{1} \mathrm{H}$ NMR spectrum of compound $\mathbf{4 d}$ exhibited a single characteristic peak at $\delta=6.17 \mathrm{ppm}$ for the $\mathrm{CH}$ group. The $\mathrm{D}_{2} \mathrm{O}$ exchangeable protons of amine and hydroxyl were observed in the region of $7-8.30 \mathrm{ppm}$ (Fig. 8b). The ${ }^{13} \mathrm{CNMR}$ spectrum of compound 4d showed a prominent peak at around $50.55 \mathrm{ppm}$, which was related to the $\mathrm{CH}$ group and the peaks at $185 \mathrm{ppm}$ and $181 \mathrm{ppm}$ correspond to the carbonyl groups (Fig. 8c).

\subsection{Proposed mechanism}

According to the proposed mechanism presented in Scheme 2, aromatic amines react with activated benzaldehyde in the presence of the catalyst through nucleophilic attack to form activated imine as an intermediate(I). Then, the intermediate(I) is attacked by 2-hydroxynaphthalene-1,4-dione through intermolecular $\mathrm{H}$-atom transfer and nucleophilic addition, which gives intermediate(II) and will undergo tautomerization to form the final products.

\subsection{Comparison of the performance of $\mathbf{f}-\mathrm{SiO}_{2} @ G O @ C o$ with some previously reported heterogenous catalysts}

Comparative tests were performed to check the ability of $\mathrm{f}$ $\mathrm{SiO}_{2} @ G o @ C o$ as opposed to other previously reported catalysts in the literature to synthesise aminonaphthoquinone. The results revealed that $\mathrm{f}-\mathrm{SiO}_{2} @ \mathrm{Go@Co}$ had a better catalytic performance than the other catalysts in terms of yield and production time (Table 5, entry 5).

\section{Conclusion}

GO@f-SiO ${ }_{2} @ \mathrm{Co}$ is a heterogenous catalyst synthesized with spherical silica particles grafted on the surface of graphene oxide with the help of ethylenediamine ligand and coordination with Co(II). The activity of the catalyst for the synthesis of aminonaphthoquinones has been assessed. The results showed that the catalyst with high catalytic activity gave excellent yield under mild conditions in a short reaction time.

\section{Conflicts of interest}

There are no conflicts to declare.

\section{Acknowledgements}

We are very grateful to the Kashan University for the financial support to run this project.

\section{References}

1 K. S. Novoselov, A. K. Geim, S. V. Morozov, D. Jiang, Y. Zhang, S. V. Dubonos, I. V. Grigorieva and A. A. Firsov, Science, 2004, 306, 666-669.

2 X. Wang, L. Zhi and K. Müllen, Nano Lett., 2008, 8, 323-327. 3 T. Ramanathan, A. A. Abdala, S. Stankovich, D. A. Dikin, M. Herrera-Alonso, R. D. Piner, D. H. Adamson, H. C. Schniepp, X. Chen, R. S. Ruoff, S. T. Nguyen,
I. A. Aksay, R. K. Prud'Homme and L. C. Brinson, Nat. Nanotechnol., 2008, 3, 327-331.

4 Q. Yang, X. Pan, K. Clarke and K. Li, Ind. Eng. Chem. Res., 2012, 51, 310-317.

5 U. K. Sur, Int. J. Electrochem., 2012, 2012, 1-12.

6 Y. Zhu, S. Murali, W. Cai, X. Li, J. W. Suk, J. R. Potts and R. S. Ruoff, Adv. Mater., 2010, 22, 3906-3924.

7 F. Bonaccorso, L. Colombo, G. Yu, M. Stoller, V. Tozzini, A. C. Ferrari, R. S. Ruoff and V. Pellegrini, Science, 2015, 347, 1246501.

8 S. C. Ray, Application and Uses of Graphene Oxide and Reduced Graphene Oxide, Elsevier Inc., 2015.

9 B. Aday, H. Pamuk, M. Kaya and F. Sen, J. Nanosci. Nanotechnol., 2016, 16, 6498-6504.

10 S. Bozkurt, B. Tosun, B. Sen, S. Akocak, A. Savk, M. F. Ebeoğlugil and F. Sen, Anal. Chim. Acta, 2017, 989, $88-94$.

11 M. D. P. Lavin-Lopez, A. Romero, J. Garrido, L. Sanchez-Silva and J. L. Valverde, Ind. Eng. Chem. Res., 2016, 55, 1283612847.

12 R. Hajian, K. Fung, P. P. Chou, S. W. Wang and K. A. Balderston, Mater. Matters, 2019, 14, 37-45.

13 D. Chen, H. Feng and J. Li, Chem. Rev., 2012, 112, 6027-6053. 14 S. R. Chaurasia, R. Dange and B. M. Bhanage, Catal. Commun., 2020, 137, 105933.

15 A. Dandia, S. Bansal, R. Sharma, K. S. Rathore and V. Parewa, RSC Adv., 2018, 8, 30280-30288.

16 A. Vijay Kumar and K. Rama Rao, Tetrahedron Lett., 2011, 52, 5188-5191.

17 Z. Li, R. Wang, R. J. Young, L. Deng, F. Yang, L. Hao, W. Jiao and W. Liu, Polymer, 2013, 54, 6437-6446.

18 T. Jiang, T. Kuila, N. H. Kim, B. C. Ku and J. H. Lee, Compos. Sci. Technol., 2013, 79, 115-125.

19 Y. J. Wan, L. X. Gong, L. C. Tang, L. Bin Wu and J. X. Jiang, Composites, Part A, 2014, 64, 79-89.

20 D. Vennerberg, Z. Rueger and M. R. Kessler, Polymer, 2014, 55, 1854-1865.

21 X. Wang, W. Xing, P. Zhang, L. Song, H. Yang and Y. Hu, Compos. Sci. Technol., 2012, 72, 737-743.

22 S. Z. Haeri, B. Ramezanzadeh and M. Asghari, J. Colloid Interface Sci., 2017, 493, 111-122.

23 X. Shi, T. A. Nguyen, Z. Suo, Y. Liu and R. Avci, Surf. Coat. Technol., 2009, 204, 237-245.

24 T. Wang, H. Ge and K. Zhang, J. Alloys Compd., 2018, 745, 705-715.

25 A. N. Banerjee, Interface Focus, 2018, 8, 20170056.

26 V. Georgakilas, J. A. Perman, J. Tucek and R. Zboril, Chem. Rev., 2015, 115, 4744-4822.

27 M. Alvand and F. Shemirani, Microchim. Acta, 2017, 184, 1621-1629.

28 N. Seifvand and E. Kowsari, RSC Adv., 2015, 5, 93706-93716.

29 R. J. R. Lumby, P. M. Joensuu and H. W. Lam, Org. Lett., 2007, 9, 4367-4370.

30 J. Wang, K. Feng, H. H. Zhang, B. Chen, Z. J. Li, Q. Y. Meng, L. P. Zhang, C. H. Tung and L. Z. Wu, Beilstein J. Nanotechnol., 2014, 5, 1167-1174. 
31 J. M. Khurana, A. Lumb, A. Chaudhary and B. Nand, Synth. Commun., 2013, 43, 2147-2154.

32 A. Feitosa Dos Santos, P. A. L. Ferraz, A. Ventura Pinto, M. D. C. F. R. Pinto, M. O. F. Goulart and A. E. G. Sant'Ana, Int. J. Parasitol., 2000, 30, 1199-1202.

33 J. Chen, Y. W. Huang, G. Liu, Z. Afrasiabi, E. Sinn, S. Padhye and Y. Ma, Toxicol. Appl. Pharmacol., 2004, 197, 40-48.

34 S. Gafner, J. L. Wolfender, M. Nianga, H. Stoeckli-Evans and K. Hostettmann, Phytochemistry, 1996, 42, 1315-1320.

35 J. E. Kuder, D. Wychick, R. L. Miller and M. S. Walker, J. Phys. Chem., 1974, 78, 1714-1718.

36 A. Esteves-Souza, K. Araújo Lúcio, A. S. da Cunha, A. da Cunha Pinto, E. L. da Silva Lima, C. A. Camara, M. Domingues Vargas and C. R. Gattass, Oncol. Rep., 2008, 20, 225-231.

37 T. M. S. Silva, C. A. Camara, T. P. Barbosa, A. Z. Soares, L. C. Da Cunha, A. C. Pinto and M. D. Vargas, Bioorg. Med. Chem., 2005, 13, 193-196.

38 V. K. Tandon, D. B. Yadav, R. V. Singh, A. K. Chaturvedi and P. K. Shukla, Bioorg. Med. Chem. Lett., 2005, 15, 5324-5328.

39 S. Siddiqui and Z. N. Siddiqui, Nanoscale Adv., 2020, 2, 46394651.
40 X. H. Yau, F. W. Low, C. S. Khe, C. W. Lai, S. K. Tiong and N. Amin, PLoS One, 2020, 15, 1-15.

41 I. Calizo, A. A. Balandin, W. Bao, F. Miao and C. N. Lau, Nano Lett., 2007, 7, 2645-2649.

42 K. N. Kudin, B. Ozbas, H. C. Schniepp, R. K. Prud'homme, I. A. Aksay and R. Car, Nano Lett., 2008, 8, 36-41.

43 P. A. Mikhaylov, M. I. Vinogradov, I. S. Levin and G. A. Shandryuk, Mater. Sci. Eng., 2019, 693, 012036.

44 S. Stankovich, D. A. Dikin, R. D. Piner, K. A. Kohlhaas, A. Kleinhammes, Y. Jia, Y. Wu, S. B. T. Nguyen and R. S. Ruoff, Carbon, 2007, 45, 1558-1565.

45 Y. Huang, W. Yan, Y. Xu, L. Huang and Y. Chen, Chem. Synth. Appl. Graphene Carbon Mater., 2016, 43-52.

46 S. Jayashree and K. Shivashankar, Synth. Commun., 2018, 48, 1805-1815.

47 D. Liu, S. Zhou and J. Gao, Synth. Commun., 2014, 44, 12861290.

48 M. Dabiri, Z. N. Tisseh and A. Bazgir, Dyes Pigm., 2011, 89, 63-69.

49 F. Mollazehi and H. R. Shaterian, Appl. Organomet. Chem., 2018, 32, 1-10. 